\title{
Epidermal growth factor in saliva and gastric juice: response to histamine
}

\author{
A M Tunio, $M$ Hobsley
}

\begin{abstract}
Epidermal growth factor (EGF) was measured in saliva and in gastric juice under basal conditions and after histamine stimulation (0.04 $\left.\mathrm{mg} \mathrm{kg}^{-1} \mathrm{~h}^{-1}\right)$. Sixty subjects studied comprised 20 normal volunteers, 20 patients with duodenal ulcer (DU), and 20 patients with nonulcer dyspepsia (NUD). There was no difference in basal salivary EGF concentrations between control and DU or control and NUD subjects, but the EGF concentration in DU patients exceeded that in NUD patients $(p<0 \cdot 05)$. Basal gastric juice concentrations of EGF were similar in all three groups. There was no difference between basal salivary and gastric EGF concentrations $(p>>0.05)$. After histamine stimulation, salivary and gastric EGF concentrations increased in all three groups: the increase was greater in gastric juice than saliva $(\mathbf{p}<\mathbf{0 . 0 0 0 1})$. There were no significant differences in the salivary EGF concentrations of controls and NUD patients, or controls and DU patients, but values were significantly higher when DU and NUD patients were compared $(p=<0 \cdot 05)$. In the gastric juice, EGF increased more in DU patients than in controls or NUD patients $(p<0.05)$. This effect was not linked to the greater acid secretion in DU than in the other groups. There was no influence of gender or smoking on the EGF concentration. This evidence suggests that the stomach itself may be able to secrete large amounts of EGF and that histamine is a potent stimulus. It is more likely that the gastric EGF is responding to the presence of a duodenal ulcer than that lack of EGF is responsible for persistence of the ulcer. (Gut 1995; 37: 335-339)
\end{abstract}

Keywords: salivary/gastric epidermal growth factor, histamine stimulation, duodenal ulcer, non-ulcer dyspepsia.

Department of Surgery, University College London Medical School, London

A $M$ Tunio

M Hobsley

Correspondence to: Professor M Hobsley, Professor M Hobsley, Department of Surgery, University College London Medical School, Charles Bel House, 67-73 Riding Hous Street, London W1P 7LD.

Accepted for publication 31 December 1994 secreted in Brunner's glands in the duodenum, submandibular, thyroid, parathyroid, adrenal, and pituitary glands and in the renal medulla. It is present in body secretions like gastric juice, urine, saliva, bile, prostatic fluid, and milk $^{2}$ and is also present in the mucosa lining the whole of the normal human digestive tract. ${ }^{34}$ EGF resists inactivation by acid and gastric proteases, and is also heat stable. In urine it is known as urogastrone. ${ }^{5}$

EGF has important functions in both protection and repair of gastroduodenal mucosa: it is known to promote mucosal DNA synthesis, cell growth, and ulcer healing. ${ }^{6}$ During pregnancy there is an increase in urogastrone production: these findings may explain why the incidence of peptic ulcer is low during pregnancy. ${ }^{7}$ Extracts of human urine promote healing of chronic ulceration in Mann-Willimson dogs. ${ }^{8}$ When urogastrone is given intravenously it inhibits gastric acid secretion ${ }^{9}$ but this does not happen when it is given by mouth. ${ }^{10}$ There is a noticeable increase in the EGF receptors around acetic acid-induced gastric ulcers in rats: the increase in the ulcer scar persists for about 25 days. ${ }^{11}$ In humans, moreover, mucosal ulceration switches on a novel linkage which secretes EGF adjacent to peptic ulcers, Crohn's ulcer, etc, ${ }^{12}$ and these findings suggests that EGF plays an important role in ulcer healing.

It has been suggested that the availability of EGF is low in patients with peptic ulcer disease and that this may contribute to the pathogenesis of ulcer disease. ${ }^{13}$ This investigation aimed to test this hypothesis by studying the ability of the stomach to secrete EGF in gastric juice and to determine whether duodenal ulcer (DU) subjects differ from normal control subjects in this respect. The EGF concentration was measured in saliva and in gastric juice during basal conditions and during maximal histamine stimulation in three groups of subjects - controls, DU patients, and nonulcer dyspepsia (NUD) patients.

\section{Subjects and methods}

SUBJECTS

Sixty subjects were included in this study. Twenty were healthy controls; the other 40 were patients being investigated for the complaint of dyspepsia with upper gastrointestinal endoscopy. Twenty of the patients were found to have a DU but in 20 others no cause for the dyspepsia was found, and they were labelled NUD. The healthy controls were chosen after taking a detailed medical history to exclude those with gastrointestinal symptoms; none were taking medication known to alter gastric function. This group included nurses, medical students, and other paramedical staff and members of the Women's Royal Voluntary Service. Fully informed consent was obtained. The study was approved by the Clinical Investigations Panel of The Middlesex 
TABLE I Age, sex, and diagnosis of subjects in the study

\begin{tabular}{lllll}
\hline Group & Total & Male & Female & $\begin{array}{l}\text { Mean age } \\
(y)(\text { median })\end{array}$ \\
\hline Control & 20 & 13 & 7 & $35(35)$ \\
Non-ulcer dyspepsia & 20 & 11 & 9 & $53 \cdot 3(43)$ \\
Duodenal ulcer & 20 & 9 & 11 & $43(53 \cdot 5)$ \\
\hline
\end{tabular}

Hospital. Details of the study population are given in Table I. The diagnostic groups were not well matched for age, although the apparent discrepancy by means magnified these differences as shown by the effect of expressing age in terms of medians.

\section{METHODS}

\section{Collection of saliva and gastric juice}

Gastric secretion studies were performed by a standard technique using an infusion of phenol red into the stomach as a non-absorbable dilution indicator. ${ }^{14}$ The studies started at $0830 \mathrm{~h}$, at which time the patient had fasted for at least 8 hours; smoking and alcohol had been proscribed for 12 hours. Furthermore, for 48 hours before the test the subjects were asked to stop $\mathrm{H}_{2}$ antagonists, proton pump inhibitors, and/or any other medication known to alter the gastric secretion and/or motility. The subject swallowed a double lumen nasogastric tube, the position of which was checked by the water recovery test. ${ }^{15}$ Aspiration of stomach contents was performed using the Sycopel Scientific pump, which alternates gentle suction at less than $100 \mathrm{~mm} \mathrm{Hg}$ for three minutes with blow back at less than $160 \mathrm{~mm} \mathrm{Hg}$ for 30 seconds. After a basal period of $1^{1 / 2}$ hours, an intravenous infusion of histamine acid phosphate, $0.04 \mathrm{mg} \mathrm{kg}^{-1} \mathrm{~h}^{-1}$ was begun together with the $\mathrm{H}_{1}$ antagonist promethazine hydrochloride (Phenergan). Promethazine hydrochloride was given at a dose of 25 $\mathrm{mg}$ at the rate of $12.5 \mathrm{mg} / \mathrm{h}$, and continued for another $1 \frac{1}{2}$ hours (maximal histamine period). Each half hour the subject was asked to provide a point sample of saliva by expectoration.

\begin{abstract}
Immediate measurements
The volume and titratable acidity of 10 minute collections were measured using a computerised method for deciding on plateau conditions. Corrections were made for pyloric losses and duodenogastric reflux ${ }^{16}$ using measurements of phenol red and sodium concentrations in the gastric juice for these purposes. The resultant pure gastric secretion was expressed as VG $\mathrm{ml} / \mathrm{h}$ and duodenogastric reflux as VR ml/h. ${ }^{17}$ Allowance was made for the subject's height. ${ }^{18}$ These measurements
\end{abstract}

were performed immediately, or (after keeping at $4^{\circ} \mathrm{C}$ ) within 2 days.

\section{Assay procedure for $E G F$}

The salivary samples, and samples of contemporaneous gastric secretion were frozen immediately at $-20^{\circ} \mathrm{C}$. The EGF concentration was measured in each of the salivary samples. The EGF concentration was also measured in the gastric juice $10 \mathrm{~min}$ sample that had been obtained at the same time as the salivary sample. The gastric juice and salivary samples were thawed for half an hour at room temperature and were analysed in duplicates. All reagents were obtained from Amersham International (Amersham Buckinghamshire, UK), and we followed the protocol suggested by Amersham for the analysis. The antiserum, raised in rabbits against human EGF, was used at a final dilution of 1:20 000. This antiserum cross reacted $88 \%$ with mouse EGF, but had no cross reactivity against unrelated gut peptides like gastrin, somatostatin, secretin, or pancreatic polypeptide. We used locally made standards (see Acknowledgements) to obtain a spline function interpolation curve: these standards were serial diluted ranging from $0.08 \mathrm{ng} / 100 \mu \mathrm{l}$ to $10 \mathrm{ng} / 100 \mu \mathrm{l}$. We used centrifugation to separate the antibody bound and free fractions. The radioactivity was then determined with an auto-gamma LKB gamma scintillation counter.

\section{STATISTICS}

All data are reported as means or medians and standard deviations. The Wilcoxon signed rank test was used with paired data, and the Mann- Whitney U test with unpaired data. Spearman's method was used to test correlation. A $p$ value less than 0.05 was considered significant.

\section{Results}

During the infusion of histamine, all the patients complained of a dry mouth and had difficulty in providing a sample of saliva. Because of the extreme viscidity of all these samples, it proved impossible to measure their volumes accurately.

The mean (SD) EGF concentrations in the three groups during the basal and histamine periods and the mean outputs of EGF in the gastric juice are given in Table II, together with differences between basal and histamine values. It is notable that the SDs are of the same magnitude as the corresponding means. This suggests that the data are not distributed

TABLE II Salivary and gastric epidermal growth factor (EGF) concentrations ( $\mathrm{ng} / \mathrm{ml}$ ) and gastric EGF output (ng/10 min) presented as mean (SD)

\begin{tabular}{|c|c|c|c|c|c|c|c|c|c|}
\hline \multirow[b]{2}{*}{ Group } & \multicolumn{3}{|c|}{ Salivary EGF } & \multicolumn{3}{|l|}{ Gastric EGF } & \multicolumn{3}{|l|}{ Gastric EGF } \\
\hline & Basal & After histamine & Difference & Basal & After histamine & Difference & Basal & After histamine & Difference \\
\hline $\begin{array}{l}\text { Control } \\
\text { Non-ulcer dyspepsia } \\
\text { Duodenal ulcer }\end{array}$ & $\begin{array}{l}3.62(2.21) \\
2.68(1.90) \\
4.59(3.08)\end{array}$ & $\begin{array}{c}7 \cdot 19(4 \cdot 64) \\
4 \cdot 42(2 \cdot 98) \\
10 \cdot 64(6 \cdot 27)^{\star}\end{array}$ & $\begin{array}{l}3.57 \\
1.74 \\
6 \cdot 05^{\star}\end{array}$ & $\begin{array}{l}4.69(6.32) \\
5.51(7 \cdot 18) \\
3.77(2 \cdot 94)\end{array}$ & $\begin{array}{l}23.33(12.57) \\
24.75(15.05) \\
53.66(37.08) \dagger\end{array}$ & $\begin{array}{l}18 \cdot 64 \\
19 \cdot 24 \\
49 \cdot 89 \dagger\end{array}$ & $\begin{array}{l}64 \cdot 0(82 \cdot 9) \\
59 \cdot 8(67 \cdot 9) \\
58 \cdot 4(83 \cdot 7)\end{array}$ & $\begin{array}{c}956.99(620 \cdot 34) \\
904 \cdot 34(756 \cdot 12) \\
1668 \cdot 56(1335 \cdot 28) \dagger\end{array}$ & $\begin{array}{c}892 \cdot 99 \\
844 \cdot 54 \\
1610 \cdot 16 \dagger\end{array}$ \\
\hline
\end{tabular}


normally and so non-parametric statistics have been used to test significance. Superscript symbols are used to indicate a significant differences. The following results are described under seven different headings.

\section{BASAL PERIOD}

There was no significant difference in the EGF concentration of control and NUD groups in either saliva or gastric juice. Salivary EGF in DU patients exceeded the EGF concentration in NUD patients $(p<0.05)$ but was not different from that in controls $(p=0.313)$. the gastric EGF concentration and output in the DU group were not different from the gastric EGF concentrations and outputs in the control and NUD groups.

\section{HISTAMINE PERIOD}

After histamine stimulation, there was an increase in the EGF concentration in all three groups and in both saliva and gastric juice.

\section{Saliva}

The effect was approximately to double the concentration, but the levels reached in the three diagnostic groups show the same pattern as that observed in the basal period. There were no differences between control and NUD $(p=0.074)$ or between DU and control groups $(p=0.069)$, but there was a highly significant difference between the DU and the NUD groups $(p=0.0002)$.

\section{Gastric juice}

The levels attained in the control and NUD groups were almost identical, but the concentration in the DU group was significantly higher than the concentrations in the other two (DU $v$ control $\mathrm{p}=0.0004$, DU $\mathrm{v}$ NUD $\mathrm{p}=0.0011)$ : indeed it was double their value. With regard to outputs, the same statements hold good (DU $v$ control $\mathrm{p}=0.0137$, DU $v$ NUD $p=0 \cdot 0265)$.

\section{BASAL-HISTAMINE DIFFERENCE}

\section{Saliva}

In saliva the rises in EGF concentration after histamine just failed to reach significance when DU and control $(p=0.065)$ and control and NUD $(p=0 \cdot 171)$ group values were compared but were significantly different between the DU and NUD groups $(p=0 \cdot 004)$. The EGF concentration in the NUD group increased by $64 \%$, that in the controls increase by $98 \%$, and the value in the DU group rose by $131 \%$.

TABLE III Comparison between men and women (Mann-Whitney $U$ test)

\begin{tabular}{|c|c|c|c|c|}
\hline \multirow[b]{2}{*}{ Group } & \multicolumn{2}{|c|}{ Gastric EGF ( $p$ value) } & \multicolumn{2}{|c|}{ Salivary EGF ( $p$ value) } \\
\hline & Basal & After histamine & Basal & After histamine \\
\hline $\begin{array}{l}\text { Control } \\
\text { Duodenal ulcer } \\
\text { Non-ulcer dyspepsia }\end{array}$ & $\begin{array}{l}0 \cdot 781 \\
0 \cdot 305 \\
0 \cdot 621\end{array}$ & $\begin{array}{l}0 \cdot 165 \\
0 \cdot 470 \\
0 \cdot 790\end{array}$ & $\begin{array}{l}0.475 \\
0.05 \\
0.470\end{array}$ & $\begin{array}{l}0 \cdot 321 \\
0 \cdot 270 \\
0 \cdot 305\end{array}$ \\
\hline
\end{tabular}

\section{Gastric juice}

In gastric juice, the increases were almost identical - about sixfold, in the control and NUD groups - but the increase in the DU group was double $(53.66 \mathrm{ng} / \mathrm{ml})$ that in the control and NUD groups $(23 \cdot 33,24 \cdot 75 \mathrm{ng} / \mathrm{ml}$ respectively, DU $v$ control $\mathrm{p}=0.0004, \mathrm{DU} \mathrm{v}$ NUD $\mathrm{p}=0.001)$. With regard to EGF output, the effect of histamine was to increase output 15 fold in the control and NUD groups and almost double that in the DU group.

\section{SALIVARY - GASTRIC EGF DIFFERENCES}

\section{Basal}

During the basal period there was a tendency for the gastric EGF concentration to exceed the salivary EGF concentration in the control and NUD groups but not in the DU patients. The means of the individual differences between gastric EGF and salivary EGF concentrations (gastric EGF minus salivary EGF) during the basal period were $+1 \cdot 059,-0.827$, and $+2.842 \mathrm{ng} / \mathrm{ml}$ in the control, DU, and NUD groups respectively. These gradients were not significantly different in control $v \mathrm{DU}$ $(p=0.597)$ or in NUD $v$ control $(p=0.136)$, but were significantly different between the NUD and DU groups $(p=0.043)$.

\section{Histamine stimulation}

After histamine stimulation the gastric EGF concentrations always exceeded those in saliva. The means of the differences between gastric EGF and salivary EGF concentration were $+16 \cdot 14,+43.03$, and $+20.32 \mathrm{ng} / \mathrm{ml}$ in the control, DU, and NUD groups respectively. These gradients were great in the DU group and less in the control and NUD groups (DU $v$ control $\mathrm{p}=0.0032$, DU $v$ NUD $p=0.023$ ) but did not differ significantly between controls and NUD (control $v$ NUD $\mathrm{p}=0.432$ ).

\section{CORRELATIONS}

There were no correlations between contemporaneous salivary EGF and gastric EGF concentrations in any group during the basal or the histamine period.

There was no significant correlation between VG and the gastric juice concentration of EGF in the stimulated secretion of any of the 60 subjects $(p=0 \cdot 422)$. Nor was there any correlation between the gastric EGF concentration and $V_{R}$ in the resting period. During histamine stimulation the mean value of $V_{R}$ was very small, $0.68 \mathrm{ml} / 10 \mathrm{~min}$.

GENDER AND AGE

None of the average EGF concentrations whether salivary or gastric or whether taken during the basal period or after histamine stimulation - showed any gender difference ( $p>0.05$ Table III). Nor was any correlation with age seen (all correlations tested by Spearman's method, $\mathrm{p}>0.05$ ). 
SMOKING

There was no difference between EGF concentrations in smokers and non-smokers $(\mathrm{p}>0.05)$.

\section{Discussion}

In this study the EGF concentration was measured simultaneously in both saliva and gastric juice in patients with DU and NUD and in normal controls. Salivary and gastric EGF concentrations were measured not only under basal conditions but also after histamine stimulation; a similar study has been reported after pentagastrin, ${ }^{19}$ but showed no increase in the gastric EGF concentration.

The gastric secretion EGF data have been presented in terms of both concentration and output but salivary EGF values can only be presented in terms of concentrations, not outputs. We collected only point-samples of saliva after each half hour of gastric juice collection. Our experience with attempts to measure the continuous production of saliva is that all such methods (repetitive expectoration, chewing of an insert substance, cannulation of duct orifices, and continuous oral aspiration) themselves stimulate the production of saliva. In this study we wished to measure the possible effects on gastric-aspirated EGF concentration of the EGF in unstimulated saliva.

The results show that during the basal period the salivary EGF concentrations were not significantly different between DU and control groups or between controls and the NUD group, but the salivary EGF concentration in the DU group was significantly higher than that in the NUD group. The relative values of salivary EGF concentrations in controls, DU, and NUD were $3.62,4.59$, and $2.68 \mathrm{ng} / \mathrm{ml}$ respectively. Other studies ${ }^{20}{ }^{21}$ have shown that the EGF concentration in saliva is lower in DU patients than in controls but we found no difference.

In basal gastric juice, the EGF concentrations were apparently similar in all three groups with no statistically significant difference between them. The EGF concentrations in gastric juice in the control, DU, and NUD groups were $4 \cdot 69,3 \cdot 77$, and $5 \cdot 52 \mathrm{ng} / \mathrm{ml}$ respectively. Previous studies ${ }^{13}$ have suggested that EGF concentrations are lower in DU patients than in controls, but there is no trend in that direction in our results.

There was no statistically significant difference between the basal salivary EGF concentration and basal gastric juice EGF concentration in any diagnostic group. It is arguable that EGF concentrations in saliva and gastric juice are similar because the swallowed saliva is not being diluted appreciably, and in that case basal gastric juice is merely swallowed saliva. We know, however, from previous work $^{22}$ that under basal conditions the stomach does produce some acid and that swallowed saliva should therefore be diluted. The fact that there is no evidence of dilution suggests that the stomach itself produces EGF and thereby maintains the EGF concentration in gastric juice at about the same level as in saliva.
After histamine stimulation there was an increase in the salivary EGF concentration in each of the three groups; it became about double that observed during the basal period. We had noted that during the histamine period subjects complained of a dry mouth and had difficulty in providing salivary samples. There is, therefore, a possibility that the rise in the EGF concentration in the saliva in all three groups could have been the effect of sialo-concentration rather than an increased output of salivary EGF. The fact that the salivary EGF concentration increased in similar proportion in all these groups favours this interpretation.

With reference to the increase in gastric juice EGF concentration after histamine, possible sources for the increase include not only the stomach itself but also reflux from the duodenum (Brunner's glands and pancreatic juice) ${ }^{19}$ and pharyngo-oesophageal secretion. Duodenogastric reflux is most unlikely as a source because there was no correlation between gastric EGF concentration and calculated reflux (VR) in basal circumstances during which there is considerable reflux present in the aspirate, and because there was virtually no reflux detectable after histamine stimulation (mean $0.68 \mathrm{ml} / 10 \mathrm{~min}$ ). The oesophagus remains a possible source, especially as it can produce large quantities of EGF when challenged by being perfused with saline or pepsin solutions. ${ }^{23}$ In our study, however, the oesophagus was only likely to have been challenged by the presence of an indwelling nasogastric tube, or by refluxing acid from the stomach. The quoted paper demonstrated that acid perfusion of the oesophagus resulted in a reduction in output of EGF from the oesophagus. ${ }^{23}$ Neither stimulus seems likely to be able to account for the massive (29 fold) increase in the gastric juice EGF output after histamine.

While the gastric juice EGF concentration and output increased after histamine in all three groups, the increase was much greater in the DU patients than in the other two groups. This difference between the DU and the other subjects could not be explained by the fact that the DU subjects also secreted more acid than the other two groups, because EGF concentration in stimulated secretion was independent of the rate of secretion. However, we know that after histamine stimulation the secretion of hydrochloric acid and pepsin increases and these increases are on average greater in DU patients than in the other groups. ${ }^{24}$ It is therefore possible that histamine stimulates EGF production in some manner that is linked to its stimulation of gastric acid or pepsin. In this respect it is interesting that there is evidence that EGF is secreted by the chief cells. ${ }^{25}$ Such a linkage would also destroy the unlikely, but at present still just tenable, hypothesis that the increase in gastric EGF production is a response to promethazine rather than to histamine. Perhaps less unlikely is the possibility that the mechanism of EGF release in response to histamine is mucosal damage produced by histamine itself, or by other agents such as Helicobacter pylori ${ }^{26}$ or aspirin ${ }^{27}$ (although none 
of these patients had been taking aspirin). We have no evidence about $H$ pylori in the subjects studied here, but it is interesting that our NUD patients, who are said to have a high prevalence of $H$ pylori, ${ }^{28}$ did not have a greater concentration or output of gastric aspirate EGF than the control group.

Our results agree with those of others 2029 that basal EGF concentrations in saliva and gastric juice are not affected by gender or chronic smoking. There was no correlation between the salivary EGF concentrations and the gastric EGF concentrations in any of the groups either in the basal or histamine period and this implies that gastric EGF is not just swallowed salivary EGF.

This study suggests that the stomach secretes considerable amounts of EGF in response to histamine. Swallowed saliva cannot be the only source of gastric EGF, even in basal circumstances, because if this were the case we would have observed lower concentrations of EGF in the gastric juice than in the saliva.

Other studies have suggested that the EGF concentration in saliva as well as in unstimulated gastric juice is lower in people with a DU than in controls. ${ }^{2025} 29-32$ Our data indicate quite the opposite in basal saliva and gastric juice, and the greater concentrations of EGF produced both in the saliva and in the gastric juice are further emphasised by the greater effect of histamine in the DU patients. The explanation of these discrepancies may lie largely in semantics and sampling errors. For example, expectoration every 10 seconds for 10 minutes, repeated expectoration for 15 minutes, and aspiration from the mouth with a dental sucker are hardly basal conditions; one study does not distinguish between gastric and duodenal ulcer; one study tries to distinguish between active and healing ulcers and has only four patients with an active DU; and in one report saliva was collected by repeated expectoration for two hours after the application of citric acid to the tongue.

In these circumstances it is difficult to accept the view that EGF deficiency in saliva or gastric juice may be a cause of duodenal ulcer. It seems more likely, however, that the presence of an ulcer stimulates the production of greater amounts of EGF, both in saliva and gastric juice, and that this response represents the attempt at ulcer healing. The antral gastritis known to be present in most DU may stimulate EGF secretion as a response to inflammation. ${ }^{12}$

The support of the Stanley Thomas Johnson Foundation of Berne, Switzerland, is gratefully acknowledged.

The EGF concentration measurements were performed in the Medical Research Laboratories of the School of Postgraduate Medicine at the University of Keele in Stoke on Trent by Elizabeth Ilderton with the active guidance and encouragement of Professor J Elder.

1 Cohen S. Isolation of a mouse submaxillary gland protein accelerating incisor eruption and eye opening in new born animal. $\mathcal{F}$ Biol Chemist 1962; 237: 1555-62.

2 Elder JB, Williams G, Lacey E, Gregory H. Cellular localisation of human urogastrone/epidermal growth factor. Nature 1978; 271: 466-7.

3 Cartlidge SA, Elder JB. Transforming growth factor a and epidermal growth factor levels in normal human gastrointestinal mucosa. Br $\mathcal{F}$ Cancer 1989; 60: 657-60.
4 Jankowski J, Murphy S, Coghill G, Grant A, Wormsley KG, Sanders DSA, et al. Epidermal growth factor receptors in the oesophagus. Gut 1992; 33: 439-43.

5 Gregory $\mathrm{H}$. Isolation and structure of urogastrone and its relationship to epidermal growth factor. Nature 1975; 257: 325-7.

6 Konturek SI, Brzozowaski T, Piastucki I, Dembinski A, Radecki T, Dembinska-Klec A, et al. Role of mucosal prostaglandins and DNA synthesis in gastric cytoprotection by luminal epidermal growth factor. Gut 1981; 22: 927-9.

7 Sandweiss DJ. Enterogastrone, anthelone and urogastrone. Gastroenterology 1945; 5: 404-41.

8 Sandweiss DJ, Salzstein HC, Farbman A. The prevention or healing of experimental peptic ulcer in Mann-Williamson dogs with anterior pituitary-like hormone (Antuitrin-S). Am F Dig Dis 1938; 5: 24-30.

9 Elder JB, Ganguli PC, Gillespie IE, Gerring EL, Gregory H. Effect of urogastrone on gastric secretion and plasma
gastrin levels in normal subjects. Gut 1975; 16: 887-93.

10 Oslen PS, Poulson SS, Therkelsen K, Nexø E. Oral administration of synthetic human urogastrone promotes the healing of chronic duodenal ulcer in rats. Gastroenterology 1986; 90: 911-7.

11 Lee H, Hansson HA, Norstrom E, Helander HF. Immunoreactivities for epidermal growth factor (EGF) and for EGF receptors in rats with gastric ulcers. Cell Tissue Res 1991; 265: 211-8.

12 Wright NA, Pike C, Eila G. Induction of a novel epidermal growth factor-secreting cell linkage by mucosal ulceration in human gastrointestinal stem cells. Nature 1990; 343: 82-5.

13 Calabrò A, Orsini B, Brocchi A, Falchini M, Fedi $\mathrm{P}$, Surrenti C. Gastric juice immunoreactive epidermal Surrenti C. Gastric juice immunoreactive epidermal Am F Gastroenterol 1990; 85: 404-7.

14 Whitfield PF, Hobsley M. A standardized technique for the performance of accurate gastric secretion studies. Agents and Action 1979; 9: 327-32.

15 Hassan MA, Hobsley M. Positioning of subject and of nasogastric tube during a gastric secretion study. $B M F$ 1970; $\mathrm{i}$ : 458-60.

16 Hobsley M. Pyloric reflux: a modification of the two component hypothesis of gastric secretion. Clinical Science and Molecular Medicine 1974; 47: 131-41.

17 Hassan MA, Hobsley $M$. The accurate assessment of maximal gastric secretion in control subjects and patients maximal gastric secretion in control subjects and

18 Hobsley M, Whitfield PF. The likelihood of a disease in relation to the magnitude of a risk factor. The example of relation to the magnitude of a risk factor. The exam
duodenal ulcer. Theoretical Surgery 1987; 2: 106-9.

19 Konturek JW, Bielanski W, Konturek SJ, Bogdal J, Oleksy J. Distribution and release of epidermal growth factor in man. Gut 1989; 30: 1194-200.

20 Ohmura E, Emoto N, Tsaushima T, Watanabe S, Takeuchi T, Kawamura M, et al. Salivary immunoreactive human epidermal growth factor (IR-hEGF) in patients with peptic ulcer disease. Hepatogastroenterol 1987; 34: 160-3.

21 Hansen G, Muller C, Sinha P, Bohnenkamp W, Kottgen E. Gastric ulcer is accompanied by a decrease of epidermal growth factor in gastric juice and saliva. $¥$ Clin Chem Clin growth factor in gastric juice

22 Faber RG, Hobsley M. Basal gastric secretion: reproducibility and relationships with duodenal ulcer. Gut 1977; 18: 57-63.

23 Sarosiek J, Hetzel DP, Yu Z, Piascik R, Li L, Rourk RM, McCallum RW. Evidence on secretion of epidermal growth factor by the esophageal mucosa in humans. Am f Gastroenterol 1993; 88: 1081-7.

24 Baron JH. Lean body mass, gastric acid and peptic ulcer. Gut 1969; 10: 637-42.

25 Konturek JW, Brzozowski T, Konturek SJ. Epidermal growth factor in protection, repair, and healing of gastroduodenal mucosa. $\mathcal{f}$ Clin Gastroenterol 1991; 13 (suppl): s88-97.

26 Lynch DAF, Mapstone NP, Lewis F, Pentith J, Axon ATR, Dixon MF, et al. Gastric juice epidermal growth factor in Helicobacter pylori associated gastritis and duodenal ulcer disease. Gut 1994; 35 (suppl 2): T123.

27 Konturek JW, Dembinski A, Domschke W, Konturek SJ. Mucosal adaptation to aspirin induced gastric damage in humans. Studies on blood flow, gastric mucosal growth, and neutophil activation. Gut 1994; 35: 1197-204.

28 Pieramico $O$, Ditschuneit H, Malfertheiner P. Gastrointestinal motility in patients with non-ulcer dyspepsia: a role for Helicobacter pylori infection? Am f Gastroenterol 1993; 88: 364-8.

29 Maccini DM, Veit BC. Salivary epidermal growth factor in patients with and without acid peptic disease. in patients with and without acid

$30 \mathrm{Li} \mathrm{L}$, Piascik R, Hetzel DP, Rourk RM, Namiot Z, Sarosiek J, McCallum RW. Effect of esophageal intraluminal mechanical and chemical stressors on salivary luminal mechanical and chemical stressors on salivary epidermal growth

31 Jones PDE, Hudson N, Hawkey CJ. Depression of salivary epidermal growth factor by smoking. $B M \mathcal{F}$ 1992; 304: $480-1$.

32 Kingsnorth AN, Smith P, Richards RC. Parotid salivary epidermal growth factor levels in human reflux oesophagitis and peptic ulcer disease. Gastroenterology 1989; 90: A257. 